\title{
Social semiotics analysis of Palestinian mathematics textbooks for eighth grade
}

\author{
Wajeeh Daher ${ }^{*}$, Ijteyad abu Thabet ${ }^{2}$ \\ ${ }^{1}$ Department of Educational Sciences , An-Najah National University, Palestine \\ ${ }^{2}$ Departmtnt of Education, Yarmouk University, Jordan \\ ${ }^{*}$ Corresponding author: daherwajeeh@gmail.com
}

\begin{tabular}{l}
\hline ARTICLE INFO \\
\hline Article history: \\
Received: 1 October 2019 \\
Revised: 9 December 2019 \\
Accepted: 10 December 2019 \\
Published online: 28 February \\
2020 \\
Published regularly: February \\
2020
\end{tabular}

Keywords:

Book analysis, mathematics books, functional grammar, social semiotics

\begin{abstract}
Mathematics textbook analysis can serve to understand the teaching and learning processes in the mathematics classroom. The present study utilizes a social semiotics framework to analyze the triangle unit of the Palestinian mathematics book for grade 8. The results of the study indicate that the authors utilized the representational aspect of the mathematical object to introduce those objects to the reader. Moreover, the nature of mathematics resulting from this unit is that of a subject that learners do not need material processes to discover, so it is enough to reason about it mentally to arrive at the mathematical objects and relations. The authors used a plural first-person pronoun to describe the need to engage with theorems and inverse theorems. They used the singular second-person pronoun to attract the attention of the reader to specific features of the mathematical objects. The authors did not use any pronoun when stating the theorem. Some of the connectors were verbs, nouns, and sentences, where the most used connector was the sentence, especially in reasoning. This use of the sentence in mathematical reasoning indicates that the authors wanted to advance the mathematical reasoning as a narrative to facilitate it for the reader.
\end{abstract}

(C) 2020 Universitas Muhammadiyah Surakarta

\section{Introduction}

Mathematics textbook analysis can serve educators and researchers to understand the teaching and learning processes in the mathematics classroom, which could impact positively teachers' attempts to influence these processes for the students to explore mathematical concepts and relations. In more detail, mathematics textbook analysis can serve to understand the performance of mathematics learners (Törnroos, 2005) their role and functions, and the interactions expected from them during their learning. These aspects are pointed at in the literature as important indicators for students' effective learning. Social semiotics takes care of these aspects when analyzing the verbal text in general and the textbook in particular. The present study utilizes this analysis framework to examine the ideational function, the interpersonal function and the textual function of the triangle unit in the Palestinian mathematics book for grade 8. The present research continues past research that used social semiotics to analyze mathematics textbooks, but here, we combined different frameworks in the analysis.

To cite this article:

Daher, W., \& abu Thabet, I. (2020). Social semiotics analysis of Palestinian mathematics textbooks for eighth grade.JRAMathEdu (Journal of Research and Advances in Mathematics Education), 5(1), 1-12. doi:https://doi.org/10.23917/jramathedu.v5i1.8960 


\section{The role of mathematics textbooks}

Jamieson-Proctor and Byrne (2008) argue that throughout history, mathematics textbooks have been identified with mathematics education, wherein many cases, historical mathematics textbooks constitute the only record of past mathematics programs. These arguments show the importance of mathematics books for the mathematics classroom and mathematics education in general. Particularly for the mathematics teacher, textbooks are a cornerstone due to the multimodality of mathematics and mathematical knowledge, where representations and dynamicity prevail.

Mathematics teachers in Palestine generally use the textbooks as a resource that can assist them in teaching the mathematical content and, at the same time, assist their students in learning this content. These teachers use the only mathematics book that is in use in the Palestinian schools; this is the book published in the ministry of education.

\section{Analyzing mathematics textbooks}

Researchers analyzed mathematics textbooks in different methods as analyzing a specific aspect of the mathematics textbook or analyzing a specific unit of the textbook using a theoretical framework. One example of analyzing a specific aspect of the mathematics textbook is that of Cai and Jiang (2017) who analyzed the problem-posing tasks in Chinese and US elementary mathematics textbooks. They said that their findings suggest a need for greater intentionality in the design and placement of problem-posing tasks in the textbooks of both countries. One example of analyzing a specific unit using a theoretical framework is that of Murdaningsih and Murtiyasa (2016) who analyzed the Eight Grade mathematics textbook of New Indonesian Curriculum (K-13) utilizing Pisa's Framework. The research results indicated that the contents of the textbook were following the PISA components. They also indicated that the problems involving the process of employing mathematical concepts, facts, procedures, and reasoning were more dominant than others.

Researchers who analyzed the Palestinian textbook used different theoretical frameworks, but primarily the NCTM Process and/or content standards (e.g., Askool, 2019). Semiotic analysis has been little used in analyzing the Palestinian mathematics textbook or other mathematics textbooks in the Arab region for that matter (For one such attempt, see Alshwaikh and Morgan (2013)). The present research attempts to do so, as this attempt will enlighten new perspectives of the Palestinian Grade 8 mathematics book, and, at the same time, it would draw the attention of researchers in the non-Western World to the advantages of using social semiotics framework in analyzing the mathematics textbooks.

\section{Related studies on social semiotic analysis of mathematics textbooks}

Halliday identifies three meta-functions of language in the frame of systemic functional linguistics. The first function is the ideational function that is the 'content function of language' (Halliday, 2007, p. 183). It is realized intransitivity and serves to represent situations and events in the world, including their entities, actions, and processes. In the ideational function, authors embody in the language their experience of the phenomena of the real world (Halliday, 1973, p. 106). The second function is the interpersonal function that is the 'participatory function of language' (Halliday, 2007, p. 184). It allows for the expression of attitudes and evaluations and is realized by mood and modality. It also allows the expression of a related set up between the authors and the reader (Halliday \& Matthiessen, 1999 , p. 7). The third function is the textual function of 
language, where the ideational and interpersonal meanings are actualized through it (Halliday, 2007: 184). It is how the text is constructed; i.e. what sort of text it is. Morgan (1996) says that this could be addressed by examining the internal features of the text, as well as its overall structure.

Several researchers used the critical analysis of texts to analyze textbooks in general and mathematics textbooks in particular (Abel \& Exley, 2008; Alshwaikh \& Morgan, 2013; Farrugia, 2018; Morgan, 1996,1998; 0'Keeffe \& O'Donoghue, 2011). Abel and Exley (2007) examined the complexity of the grammatical structure of six worded mathematics texts. These texts constituted part of a mathematics worksheet typical for assessing the competencies of early years' students regarding the relating of everyday experiences to mathematical operations of addition, subtraction, division, and multiplication. To do that, they used Functional Grammar, in terms of mood type, clause structure, and cohesion, to analyze the means of representing experience and instruction in these worded math texts. All the six worded mathematics problems followed the same pattern for they included two statements that differed from each other in structure and function. In each of the six texts, the first statement provided information about an everyday event while the second requested information. The first statement was declarative, starting with a participant in the Theme position. The second statement started with 'How many...; i.e. with a WHinterrogative, which required a demanding, lengthy and complex response.

Alshwaikh and Morgan ( $\underline{2013}$ ) compared the congruence unit in the Palestinian and the English textbooks. This unit is part of the Palestinian school mathematics textbook for grade 7. Analyzing the unit in the two books, they looked at the following two themes: specialization (the extent of using specialized text), and earner agency (the kind of activity the learner is expected to engage in and the choices available to them). The authors concluded that the Palestinian unit used a specialized discourse that emphasized formally defined objects and reasoning about properties, while the English text uses a mixed discourse that emphases processes of practical manipulation and visualization. At the same time, both textbooks expected to the learner engage in material activity.

O'Keeffe (2013), using a combination of the four key elements of textbook analysis, to investigate the effectiveness of the current Irish Junior Cycle mathematics textbooks for developing students' understanding and motivation. These four elements are content, structure, expectation, and language. Content is composed of four components: motivational factors (historical notes, applications, and photographs), comprehension cues (colour and graphics), technical aids (calculators and computers), and philosophical position (predominant philosophy). On the other hand, the structure is composed of five components: reference (pronominal, comparative, articles), substitution (nominal and clausal), ellipsis (nominal and verbal), conjunction (additive and temporal), and lexical (same item, general item). Moreover, the expectation is composed of what we expect from the teacher and students.

Farrugia (2018) studied how students used English and Maltese languages to learn mathematics. She concluded that the translanguaging represented an integrated system as each language played an intricate role in realizing the three elements of the mathematics register. Furthermore, the students read diagrams and symbols in English, which pointed at the English language as linking various semiotic systems. Nouns and noun phrases were embedded into Maltese sentence structure, but some words that served as adjectives or verbs in English were turned into nouns in Maltese. 
Research rationale, aims, and questions

The present research is interested in analyzing the Grade 8 Palestinian book to enlighten the social aspects of learning in this book, which could serve to develop this book to facilitate students' understanding of mathematics. This would also benefit educators, in general, to assess students' learning processes of mathematical ideas through textbooks. Little research has used the social semiotics framework to analyze the mathematics textbook. This framework enlightens the important aspect of the text, especially the mathematics textbook as the ideational function, the interpersonal function, and the textual function. The following research questions follow:

1. What are the features of the ideational function of the Grade 8 mathematics textbook?

2. What are the features of the interpersonal function of the Grade 8 mathematics textbook?

3. What are the features of the textual function of the Grade 8 mathematics textbook?

\section{Research Methods}

\section{Textbook selection}

The mathematics textbook for grade 8 that we analyze in the present paper was used in the mathematics classroom from 2002-2003 until 2016-2017. It is the book that publishes the Palestinian ministry of education. This book is the only mathematics book used in Palestinian schools. The mathematics textbook for grade 8 consists of two parts. The first part, consisting of 143 pages, includes four units (real numbers, the triangle, commercial transactions, statistics), in addition to two appendices, one for computer applications using Excel, while the second appendix includes trigonometrical tables. The second part, consisting of 143 pages, includes four units (factorization, quadrilaterals, trigonometric ratios, probability), in addition to an appendix of computer applications.

The text that we analyzed is the second lesson of the triangle unit in the first part of the mathematics textbook for grade 8. This lesson extends over the pages 52-61. This lesson consists of five sections. The first section is the introduction section. It consists of three sub-sections: reviewing material related to the isosceles triangle, questions about the reflection in an isosceles triangle, and conclusions regarding the properties of the isosceles triangle (the equality of the basic angles and the relation between the special lines in the triangle). The second section engaged the proof of the theorem about the angles at the isosceles triangle basis. The third section was about the consequences of this theorem (three consequences regarding the special lines in the triangle). The fourth section involved an inverse theorem talking about the triangle in which two angles are equal, while the fifth section involved other inverse theorems about triangles in which conditions about its special lines are given, for example when the height of the triangle on its basis halves it.

\section{Textbook analysis}

For the present research, content analysis, in its deductive form, was used. In content analysis, raw data is condensed into categories or themes by utilizing valid inference and interpretation. Deductive reasoning can also be used to generate concepts from theory (Patton, 2002). Using deductive reasoning we looked for themes related to the three social semiotics functions that utilize mainly language analysis. This language analysis depends on Halliday (1985), Morgan (1996,1998), O'Keeffe and O'Donoghue (2011), and Alshwaikh and Morgan ( $\underline{2013})$. 
In more detail, we depended on Morgan (1998) and on O'Keeffe and O'Donoghue (2011) to analyze the ideational function of the textbook. When analyzing the human role, we paid attention to the different types of human processes (material, mental, relational, verbal, behavioral and existential processes), while when we analyzed the role of the objects, we differentiated among representational, relational and basic or derived aspects. The representational aspect concerns representation of the mathematical objects (geometric, algebraic, numeric, etc.), while the relational aspect concerns mathematical relations between mathematical objects. The basic or derived aspect concerns the basic mathematical entities or relations vs. the entities or relations that could be derived from the basic ones. For example, we considered the relation "If two sides of a triangle are congruent, the angles opposite them are congruent" as basic, whereas the relation "The altitude to the base of an isosceles triangle bisects the vertex angle" as derived. Table 1 represents how we analyzed the ideational function.

Table 1

Table for the analysis of the ideational function

\begin{tabular}{|c|c|c|c|c|}
\hline \multirow[t]{2}{*}{ Process } & Human & & Mathematicalobject & \\
\hline & Particular & General & representational relational & Basic/derived \\
\hline $\begin{array}{l}\text { material } \\
\text { mental } \\
\text { relational } \\
\text { verbal } \\
\text { behavioral } \\
\text { existential }\end{array}$ & & & & \\
\hline
\end{tabular}

Moreover, we depended on Morgan (1996) to analyze the interpersonal function of the text, where this function examines the interaction between the social and the personal in the textbook, especially between the textbook author and readers (O'Keeffe \& O'Donoghue, 2011). It also included the degree of author's authority towards the reader, towards mathematics and the particular mathematical task. Morgan (1995) describes how to examine this function: analyzing the use of personal pronouns, imperatives and passive sentences, as well as the use of informal speech. Table 2 represents how we analyzed the interpersonal function.

Table 2

Table for the analysis of the interpersonalfunction

\begin{tabular}{|c|c|c|c|c|c|c|}
\hline \multirow[t]{2}{*}{ Activity } & Pronouns & \multicolumn{5}{|c|}{ Verbs } \\
\hline & we I & Other pronouns & All pronouns & Imperative & Other verbs & All verbs \\
\hline
\end{tabular}

Furthermore, we depended on O'Keeffe and O'Donoghue (2011), Martin and Rose

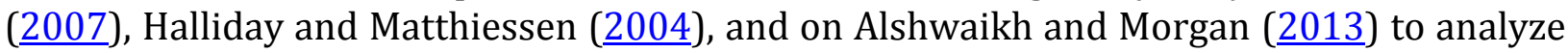
the textual function of the textbooks. O'Keeffe and O'Donoghue (2011) analyzed the textual function by looking at the reasoning conjunctions (e.g. 'a result of'), logical reasoning conjunctions (e.g. 'thus') and reasoning imperatives (e.g. 'next').

We utilized the conjunctions theme described by Martin and Rose (2007), as well as the continuatives theme described by Halliday and Matthiessen (2004). Martin and Rose (2007)divided conjunctions into two categories; external and internal conjunctions, where external conjunctions are used to link objective events. Table 3 shows those external conjunctions, while Table 4 shows internal conjunctions, in terms of their roles of constructing logical relations in the text. 
According to Halliday and Matthiessen (2004), continuatives are small sets of words that link or indicate a move in a discourse. There are three kinds of continuatives: addition, comparison and time. The addition continuative has only sub-type: neutral. The comparison continuative has three sub-types: neutral, less than and more than, while the time continuative has four sub-types: sooner, longer, persistent, repetitive.

Table 3

External conjunctions according to Martin and Rose (2007)

\begin{tabular}{|c|c|c|}
\hline Conjunction type & Sub-type & Examples \\
\hline Addition & $\begin{array}{l}\text { addition } \\
\text { alternation }\end{array}$ & $\begin{array}{l}\text { and, besides, in addition } \\
\text { or, if not - then, } \\
\text { alternatively }\end{array}$ \\
\hline Comparison & $\begin{array}{l}\text { similarity } \\
\text { contrast }\end{array}$ & $\begin{array}{l}\text { like, as if, similarly } \\
\text { but, whereas, on the other } \\
\text { hand }\end{array}$ \\
\hline Time & $\begin{array}{l}\text { successive } \\
\text { simultaneous }\end{array}$ & $\begin{array}{l}\text { then, after, subsequently; } \\
\text { before, previously } \\
\text { while, meanwhile, at the } \\
\text { same time }\end{array}$ \\
\hline Consequence & $\begin{array}{l}\text { cause } \\
\text { means } \\
\text { purpose } \\
\text { condition }\end{array}$ & $\begin{array}{l}\text { so, because, since, therefore } \\
\text { by, thus, by this means } \\
\text { so as, to; lest, for } \\
\text { fear of } \\
\text { if, provided that; unless }\end{array}$ \\
\hline
\end{tabular}

Table 4

Internal conjunctions according to Martin and Rose (2007)

\begin{tabular}{|c|c|c|}
\hline Conjunction type & Sub-type & Examples \\
\hline Addition & $\begin{array}{l}\text { additive } \\
\text { alternative }\end{array}$ & $\begin{array}{l}\text { further, in addition } \\
\text { alternatively }\end{array}$ \\
\hline Comparison & $\begin{array}{l}\text { similar } \\
\text { different }\end{array}$ & $\begin{array}{l}\text { similarly, for instance } \\
\text { on the other hand, in } \\
\text { contrast }\end{array}$ \\
\hline Time & $\begin{array}{l}\text { successive } \\
\text { simultaneous }\end{array}$ & $\begin{array}{l}\text { firstly, finally } \\
\text { at the same time }\end{array}$ \\
\hline Consequence & $\begin{array}{l}\text { concluding } \\
\text { countering }\end{array}$ & $\begin{array}{l}\text { therefore, in conclusion, } \\
\text { thus } \\
\text { admittedly, nevertheless }\end{array}$ \\
\hline
\end{tabular}

\section{Validity and Reliability of the Analysis Method}

The validity of the research analyzing procedure was verified by keeping theoretical saturation that tries to find all the themes and categories related to a phenomenon. Ensuring that no new category type will appear ensures that the research phenomenon has been explored in its whole. What also ensures the validity of the analyzing method is the description of each category, which ensures that every category is well developed regarding its properties and dimensions (Strauss \& Corbin, 1998, p. 212). The previous processes demonstrate that the variation of the phenomenon has been explored.

Lincoln and Guba (1985) say that validity does not exist without reliability, so satisfying validity also ensures the satisfying of reliability. This means that theoretical saturation conserves the validity of the research procedure besides its reliability. Two experienced coders (the two authors) coded the resulting themes and categories, searching for ideational, interpersonal and textual themes and categories. The agreement between the coders (Cohen's Kappa coefficient), when satisfied, ensures the reliability of the 
qualitative coding. Computing Cohen's Kappa coefficient resulted in 0.845 to 0.907 for the various categories related to the three functions of social semiotics. These values ensured accepted the agreement between the two coders.

\section{Results and Discussion}

In the present research, we present an analysis of the isosceles triangle lesson in the Palestinian mathematics textbook for grade eight. The unit of analysis was the activity (question, task, presentation of learning material). We found five sections in the lesson (introduction, proof of the theorem about the angles at the isosceles triangle basis, consequences of this theorem, the main inverse theorem, and other inverse theorems about triangles in which conditions about its special lines are given). Below is an analysis of the first section (introduction) for each of the three metafunctions: ideational, interpersonal and textual. This section includes as described above three sub-sections: reviewing material related to the isosceles triangle, questions about the reflection in an isosceles triangle, and conclusions regarding the properties of the isosceles triangle.

\section{The ideational function}

In the reviewing sub-section of the first section, the authors utilized the representational aspect of the mathematical object, by drawing an isosceles triangle with a reflection axis. The drawing was on the left of the verbal text, indicating the subordinate character of the drawing concerning the verbal text (The Arabic text goes from right to leave, which makes the left subordinate to the right in a page that is partitioned into two parts). The authors described all the properties previously learned by the readers, without giving them the chance to discuss them (for example through posing questions). Moreover, the authors presented another representational aspect of the topic by attracting the attention of the reader to the similarity of the reflection axis and the mirror. Table 5 shows the frequency of the aspects of the mathematical objects in the analyzed lesson.

Table 5

Aspects of mathematical objects and their frequency

\begin{tabular}{lc}
\hline Aspects of mathematical objects & Frequency \\
\hline Basic or derived & 9 \\
Relational & 3 \\
Representational & 32 \\
\hline
\end{tabular}

Table 5 shows that the representational aspect of the mathematical object was mostly used by the authors.

In annex, the learner is expected in the first sub-section of the first section to be involved with the material process (folding) to verify the fact that the height of the triangle is the reflection axis. In the second sub-section of the first section, the authors asked the reader questions to be answered with the help of the representational aspect of the topic, specifically through the mirror as representing the reflection axis. Moreover, here the process expected from the reader was the mental: to imagine the mathematical situation, think about it and answer the questions. In the third subsection of the first section, the authors asked the reader questions to arrive at generalizations about the properties of the isosceles triangle (the relation between the special lines in the triangle). The reader is expected to arrive at these generalizations through using the mirror as a reflection axis, and through using the answers of the previous questions (connecting with previous knowledge); i.e. through mental processes. 
Talking about the five sections of the lesson, the authors describe the properties of the isosceles triangle in the first section using material, mental and relational processes to reason about these properties. For example, the reader was asked to use folding to see that a line is the reflection axis of the isosceles triangle. The learner in the second section is expected to engage in behavioral processes (for example, paying attention to some equalities between the edges of two triangles) and in mental processes (for example, engaging in thinking about geometric equalities). The learner in the third to the fifth sections is expected to engage with mental and relational processes about geometric relations linked with the isosceles triangle topic. In those three sections, the learner is also expected to engage with behavioral and mental processes while finding unknown angles, unknown edges, and reasoning about each step. Table 6 shows the frequency of the processes in the five sections of the lesson.

Table 6

Frequencies of the processes

\begin{tabular}{lc}
\hline Process & Frequency \\
\hline Material & 9 \\
Mental & 12 \\
Relational & 16 \\
Verbal & 2 \\
Behavioral & 2 \\
Existential & 0 \\
\hline
\end{tabular}

Table 6 shows that the learner performs mainly relational and mental processes, and then material processes.

\section{The interpersonal function}

In the first section of the lesson, the authors used the singular second-person pronoun (you learned, does it help you? You will learn). In the second to the fourth sections, the authors used two different types of pronouns: plural first-person pronoun (we will learn, we used previously, we will name it, it will enable us, we conclude) and singular second-person pronoun (note that, look at). The authors used a plural first-person pronoun to describe the need to justify theorems, and to reason about the inverse theorem. The authors used the singular second-person pronoun to attract the attention of the reader to specific features of the mathematical objects, in our case the isosceles triangle, the angles, and edges of the isosceles triangle. In the fifth section, the authors changed the way of using pronouns, here not using any pronoun, when stating the theorem. Nevertheless, the authors used the singular second-person pronoun to request the reader to perform some actions (compute, find, I find, show, I show).

\section{The textual meta-function}

Talking about the five sections of the lesson and the conjunctive adjuncts, the authors used internal conjunctions more than external conjunctions. In the first section of the lesson, the external conjunctions used were the addition conjunction - specifically the additive one (using for example 'and' to combine between isosceles and equilateral triangles), the time conjunction - specifically the successive one (using for example "before' to talk about the two types of triangles as a material that has been taught), and the comparison conjunction - specifically the 'similar' one (using for example 'like' to indicate the similarity of the reflection axis to the mirror). Moreover, in the first section of the 
lesson, the internal conjunctions used were the time conjunction - specifically the successive one (using 'next', 'first', 'second', and 'third'. For example, the authors used 'next' to suggest answering some questions depending on the similarity between the reflection axis and the mirror). Another internal conjunction that was used intensively is the consequence conjunction, specifically, 'thus' and 'therefore' to reason about the causes of mathematical relations. Table 7 shows the frequencies of the conjunctive adjuncts in the lesson.

Table 7

Frequencies of the conjunctive adjuncts in the analyzed lesson

\begin{tabular}{llc}
\hline & Conjunctive adjuncts & Frequency \\
\hline internal conjunctions & time conjunction & 8 \\
& consequence conjunction & 7 \\
external conjunctions & addition conjunction & 4 \\
& time conjunction & 3 \\
& comparison conjunction & 3 \\
\hline
\end{tabular}

Table 7 shows that the used internal conjunctions were more than the external ones.Some of the connectors were verbs, nouns, and sentences. Examples of such connectors are 'you got to know', 'you can depend', 'we can conclude' and 'what is the evidence?'The use of the conjunctive adjuncts in the four other sections is similar, but in the second section, the authors used an external conjunction; the consequence conjunction - specifically the 'condition' and the 'purpose' ones (using for example 'if' to indicate the congruence of two triangles as condition for the equality of two angles).

Talking about the continuatives in the five sections of the lesson and, the use of these textual themes was little. Only in the fourth section, the authors used the comparison continuative - specifically the 'less than' one (using 'just' to indicate that only one way of solution should be applied to a problem).

We tried in this research to analyze the lesson of an isosceles triangle in the Palestinian textbook for the eighth-grade mathematics book using the three meta-functions of the text (Halliday, 1985; Morgan, 1995). To do that, we combined between different frameworks developed in the past (Alshwaikh\& Morgan, 2013; Morgan, 1996; O'Keeffe \& O'Donoghue, 2011; Martin \& Rose, 2007) that suggested theoretical frameworks to analyze three meta-functions to analyze mathematics textbooks.

\section{The ideational function}

The research results indicate that the authors utilized the representational aspect of the mathematical object to introduce those objects to the reader and make her work with them. Presenting on the stage the representational objects could mean the obscuring of the writer's presence as an author as well as a mathematician (Morgan, 1996). The research results also indicate that the most used process in the triangle unit was the relational process (16 out of 41). The next used processes were the mental (12), the material (9), the behavioral (2) and the verbal (2). The excessive use of the relational, mental and material processes by the authors agrees with the common state found in mathematical texts (Morgan, 1996). On the other hand, the fact that the most used process in the text is relational implies that the authors look at mathematics as "a system of relationships between objects or between objects and their properties" (ibid, p. 4). Moreover, the fact that the next most used process is the mental process implies that the authors look at mathematics as "a pre-existing entity that is sensed (discovered) by mathematicians" (ibid, 
p. 4). Furthermore, it could be said that the nature of mathematics resulting from this lesson is that of a subject that does not need material processes to discover it, and it is enough to think and reason about it mentally to arrive at relations that the mathematical situations satisfy.

In addition to the above, it could be argued that the Palestinian text construes the learner as a 'thinker' who is engaged with mental and relational processes, which agreed with Alshwaikh and Morgan (2013) who pointed at the same phenomenon regarding the Palestinian curriculum.

\section{The interpersonal meta-function}

The research results indicate that the authors varied their use of the pronouns according to the function of their processes. More specifically, they used the plural firstperson pronoun to talk about issues related to reasoning, and the singular second-person pronoun for two goals: to attract the attention of the reader to specific features of the mathematical objects and to request the reader to perform some actions. It seems that the authors considered the reasoning process a difficult one, so it needs the participation of a group of learners consisting of the readers (student learners) as well as the author s (the experienced individuals). This made the authors use the plural first person. This use of the plural first pronoun can also suggest (Pimm, 1987 pp. 69-70) that the expert persons are associating themselves with some other persons, thereby appealing to an 'expert' community that provides authority to impose a certain type of classroom practice, here proving. Furthermore, attention has been paid to using the pronoun 'you' to describe generalization in classroom talk by Rowland $(\underline{1992,1999})$. Here the textual use of you was done to request action of the reader.

Furthermore, Rowland (1999) says that pronominal variations "can be associated with delicate shifts of social positioning of the speaker concerning his/her audience (p. 20). It could be said that pronominal variations in the studied mathematical text are also due to shifts of social positioning of the authors concerning their readers. More specifically, the authors guided the readers in their reasoning process but changed their relationship with the readers to a more formal one when requesting them to do some needed processes, in our case to perform some mathematical actions.

\section{The textual meta-function}

The research results indicate that the internal conjunctions are used more than the external conjunctions, which implies that the authors attempt to establish the studied mathematical text as such, more than to represent the world outside the text (Schleppegrell, 2004). Some of the connectors were verbs, nouns, and sentences, where the most used connector was the sentence. This happened especially when the author reasoned or proved a mathematical statement (So the two triangles are congruent) or theorem (If the two sides of a triangle are equal then its base angles are equal). This use of sentences in mathematical reasoning, as if part of a story, could indicate that the author wanted to advance the mathematical reasoning as a narrative that makes this reasoning easier for the reader.

\section{Conclusion}

The present study used the three meta-functions of language in the frame of systemic functional linguistics to analyze the isosceles triangle lesson in the Palestinian mathematics textbook for grade eight. The results of the study indicate that the authors utilized the 
representational aspect of the mathematical object to introduce those objects to the reader. Moreover, the nature of mathematics resulting from this lesson is that of a subject that learners do not need material processes to discover it, so it is enough to reason about it mentally to arrive at relations that the mathematical situations satisfy.

The authors used a plural first-person pronoun to describe the need to justify theorems, and to reason about the inverse theorem. Moreover, the authors used the singular second-person pronoun to attract the attention of the reader to specific features of the mathematical objects. The authors did not use any pronoun when stating the theorem.

Some of the connectors were verbs, nouns, and sentences, where the most used connector was the sentence, especially in reasoning. This use of the sentence in mathematical reasoning indicates that the author wanted to advance the mathematical reasoning as a narrative that makes this reasoning easier for the reader.

The present study analyzed the version of the Palestinian mathematics book that was used until 2016-2017. Future research needs to study the newer version and its difference from the studied version. This would enable us to study the development of the ministry of education's view on the nature of mathematics and of doing mathematics.

\section{Bibliography}

Abel, K., \& Exley, B. (2008). Using Halliday's functional grammar to examine early years worded mathematics texts. The Australian Journal of Language and Literacy, 31(3), 227.

Alshwaikh, J., \& Candia Morgan. (2013). Analysing the Palestinian school mathematics textbooks: A multimodal (multisemiotic) perspective. In Smith, C (Ed.). Proceedings of the British Society for Research into Learning Mathematics, (pp. 70-75). Retrieved from http://hdl.handle.net/20.500.11889/2474

Askool, M. (2019). The analysis of Grade 9 Palestinian mathematics book in light of NCTM standards.Journal of Elementary School for Educational and Humanistic Sciences, 11(1), 337-355 (In Arabic). Retrieved from http://www.becmiq.org/papers/uobj paper 2019 2166696.pdf

Cai, J., \& Jiang, C. (2017). An analysis of problem-posing tasks in Chinese and US elementary mathematics textbooks. International Journal of Science and Mathematics Education, 15(8), 1521-1540. https://doi.org//10.1007/s10763-016-9758-2

Farrugia, M. T. (2018). A functional linguistics analysis of a mathematics register expressed through two languages. In N. Planas, \& M. Schütte (Eds.). Proceedings of the IV ERME Topic Conference 'Classroom-Based Research on Mathe-Matics and Language', (pp. 5764). Dresde, Germany: ERME. Retrieved from https://hal.archives-ouvertes.fr/hal$01856477 /$ document

Halliday, M. A. K. (1973). Explorations in the functions of language.London: Edward Arnold.Retrieved from https://eric.ed.gov/?id=ED095550

Halliday, M. A. K. (1985). An Introduction to Functional Grammar (E. Arnold, ed.). London: Edward Arnold.

Halliday, M. A. K. (2007). Language as social semiotic: Towards a general sociolinguistic theory. In M. A. K. Halliday. Language and Society, (pp. 169-202). Edited by J. Webster. London: Continum.

Halliday, M.A.K., \& Matthiessen, C. M. I. M. (1999).Construing experience through meaning: a language-based approach to cognition. London: Cassell.

Halliday, M. A. K., \& Matthiessen, C. M. I. M. (2004). An Introduction to Functional Grammar(Third edit). London : Hodder Arnold.

Jamieson-Proctor, R., \& Byrne, C. (2008). Primary teachers' beliefs about the use of 
mathematics textbooks. In: M. Goos, R. Brown \& K. Makar (Eds.), Proceedings of the 31st Annual Conference of the Mathematics Education Research Group of Australasia, (pp. 295-302). Brisbane. QLD: MERGA. Retrieved from http://www.merga.net.au/documents/RP332008.pdf

Martin, J. R., \& Rose, D. (2007). Working with Discourse (2nd ed.). New York, NY: Continum. Morgan, C. (1996). "The language of mathematics": towards a critical analysis of mathematical text. For the Learning of Mathematics. 16(3), 2-10. Retrieved from https://www.jstor.org/stable/40248208?seq=1

Morgan, C. (1998). Writing Mathematically: The Discourse of Investigation. London: Falmer. Murdaningsih, S., \& Murtiyasa, B. (2016). An Analysis on Eight Grade Mathematics Textbook of New Indonesian Curriculum (K-13) Based on Pisa's Framework. JRAMathEdu (Journal of Research and Advances in Mathematics Education), (1), 14-27. https://doi.org/10.23917/jramathedu.v1i1.1780

O'Keeffe, L. (2013). A Framework for Textbook Analysis. International Review of Contemporary Learning Research. International Review of Contemporary Learning Research, 2(1), 1-13. Retrieved from https://platform.almanhal.com/Files/2/46765

O'Keeffe, L., \& O'Donoghue, J. (2011). Mathematics Textbook Analysis: The Significance of Textbook Features to Student Learning. In Proceedings of the Seventh Congress of the European Society for Research in Mathematics Education. Rzeszów, Poland: University of Rzeszów.

Pimm, D. (1987). Speaking Mathematically: Communication in Mathematics Classrooms.London: Routledge and https://doi.org/10.4324/9781315278858

Rowland, T. (1992). Pointing with pronouns. For the Learning of Mathematics, 12(2), 44-48. Retrieved from www.jstor.org/stable/40248049

Rowland, T. (1999). Pronouns in mathematics talk: power, vagueness and generalisation. For the Learning of Mathematics, 19(2), 19-26. Retrieved from https://www.jstor.org/stable/40248049?seq=1

Schleppegrell, M. J. (2004). The language of schooling: A functional linguistics perspective New Jersey, USA: Lawrence Erlbaum Associates.

Törnroos, J. (2005). Mathematics textbooks, opportunity to learn and student achievement. Studies in Educational Evaluation, 31(4), 315-327. https://doi.org//10.1016/j.stueduc.2005.11.005 